\title{
Letter from the Editor-in-Chief: Transitions
}

\author{
M. Maral Mouradian
}

Published online: 7 January 2014

(C) The American Society for Experimental NeuroTherapeutics, Inc. 2014

After a decade of remarkable growth and achievement under the capable leadership of the founding Editor-in-Chief, Alan I. Faden, M.D., 2014 marks a transition for Neurotherapeutics. I am honored to have been selected by the Publications Committee of the American Society for Experimental NeuroTherapeutics (ASENT), which owns the journal, to fill this position following a search that began early in 2013. I am excited about this appointment and appreciate the opportunity to take Neurotherapeutics to the next level.

Publishing a journal, and particularly one that covers all conditions that affect the nervous system, requires a team effort. I am grateful to have two outstanding Associate Editors join me in this endeavor: Rajiv R. Ratan, M.D., Ph.D., Executive Director of Burke Medical Research Institute and Associate Dean of Weill Cornell Medical College, and Gregory K. Bergey, M.D., Director of the Johns Hopkins Epilepsy Center and Vice-Chair for Research in the Department of Neurology at Hopkins. In addition, the wide-ranging expertise of the editorial board members is critical to ensure the highest quality of publications. The Editorial Manager, Linda Powell, who has served the journal since its inception, will continue to provide steady support for its operations, and the commitment of the publishing staff at Springer is vital to its continued success.

The mission of Neurotherapeutics remains the same. We will continue to publish selected, high-quality papers that focus on translating therapeutic discoveries in the laboratory to the clinic for diseases of the nervous system. This original vision, shared with ASENT, has made the journal the first of its kind to fill a unique niche in scientific publishing. Now, more than ever, translational research in the neurosciences is the critical bridge to develop much needed therapies and biomarkers of treatment response for neurologic, neurodevelopmental, and psychiatric disorders.

The format of Neurotherapeutics will continue to be a hybrid between invited critical reviews that focus on a special topic in each issue and unsolicited, exceptional original research articles describing translational neuroscience ranging from early-stage therapeutic discoveries to animal model testing to clinical trials. Neurotherapeutics was initially founded as a review journal, and began to publish original research articles in 2011. We hope to expand the number of published original articles while maintaining the highest standards of scientific rigor. We also hope to be able to add a new feature of "controversies" in translational neurotherapeutics, where appropriate. We will strive to have a shorter turnaround time in getting editorial decisions to authors of original articles, with a significant proportion of manuscripts receiving a decision after an in-house screening process.

Finally, my deep gratitude goes to the editorial leadership whose terms just ended, including Dr. Faden and Associate Editors Drs. Rohit Bakshi and David Fink. Their generous support in recent months has been instrumental in ensuring a seamless transition. Additionally, the impressive progress they have made in advancing the journal to where it is today will guide the new leadership in forging ahead and building on past strengths. As the new editor, I am open to new ideas and suggestions, and invite you to contact me through the journal at neurotherapeuticsjournal@gmail.com.

\author{
M. Maral Mouradian \\ Editor-in-Chief
}

\footnotetext{
M. M. Mouradian $(\bowtie)$

Rutgers Robert Wood Johnson Medical School,

Piscataway, NJ, USA

e-mail: neurotherapeuticsjournal@gmail.com
} 